\title{
Papers
}

\section{Cannabis intoxication and fatal road crashes in France: population based case-control study}

Bernard Laumon, Blandine Gadegbeku, Jean-Louis Martin, Marie-Berthe Biecheler, the SAM Group

\begin{abstract}
Objectives To evaluate the relative risk of being responsible for a fatal crash while driving under the influence of cannabis, the prevalence of such drivers within the driving population, and the corresponding share of fatal crashes.

Design Population based case-control study.

Participants 10748 drivers, with known drug and alcohol concentrations, who were involved in fatal crashes in France from October 2001 to September 2003.

Main outcome measures The cases were the 6766 drivers considered at fault in their crash; the controls were 3006 drivers selected from the 3982 other drivers. Positive detection of cannabis was defined as a blood concentration of $\Delta^{9}$ tetrahydrocannabinol of over $1 \mathrm{ng} / \mathrm{ml}$. The prevalence of positive drivers in the driving population was estimated by standardising controls on drivers not at fault who were involved in crashes resulting in slight injuries.

Results 681 drivers were positive for cannabis (cases 8.8\%, controls 2.8\%), including 285 with an illegal blood alcohol concentration $(\geq 0.5 \mathrm{~g} / \mathrm{l})$. Positive cannabis detection was associated with increased risk of responsibility (odds ratio 3.32 , $95 \%$ confidence interval 2.63 to 4.18 ). A significant dose effect was identified; the odds ratio increased from 2.18 (1.22 to 3.89) if $0<\Delta^{9}$ tetrahydrocannabinol $<1 \mathrm{ng} / \mathrm{ml}$ to 4.72 (3.04 to 7.33 ) if $\Delta^{9}$ tetrahydrocannabinol $\geq 5 \mathrm{ng} / \mathrm{ml}$. The effect of cannabis remains significant after adjustment for different cofactors, including alcohol, with which no statistical interaction was observed. The prevalence of cannabis (2.9\%) estimated for the driving population is similar to that for alcohol $(2.7 \%)$. At least $2.5 \%(1.5 \%$ to $3.5 \%)$ of fatal crashes were estimated as being attributable to cannabis, compared with $28.6 \%$ for alcohol $(26.8 \%$ to $30.5 \%)$.

Conclusions Driving under the influence of cannabis increases the risk of involvement in a crash. However, in France its share in fatal crashes is significantly lower than that associated with positive blood alcohol concentration.
\end{abstract}

\section{Introduction}

Experimental studies have shown that consumption of cannabis diminishes the faculties needed for vehicle driving. ${ }^{12}$ These effects are sometimes perceptible on driving simulators ${ }^{3-5}$ or in real situations. ${ }^{6}$ Epidemiological studies have often focused on responsibility for a crash; results have varied with respect to the increase in responsibility attributable to cannabis consumption. $^{89}$ The underlying difficulty is in the absence of a synchronous relation between a change in behaviour and the presence of cannabinoids in the blood or urine. ${ }^{10}$ Recent studies have highlighted the importance of focusing analyses on the detection of $\Delta^{9}$ tetrahydrocannabinol in the blood. ${ }^{11}{ }^{12}$ However, the low number of drivers positive for $\Delta^{9}$ tetrahydrocannabinol and the common association of cannabis and alcohol hamper the detection of effects entirely attributable to cannabis. ${ }^{13}$

In 1999, before considering changes in drug legislation, the French government wished to obtain reliable epidemiological data, especially on the role of cannabis in the occurrence of crashes. Systematic research was organised in France, from October 2001 to September 2003, into drug consumption in drivers involved in fatal road crashes.

\section{Methods}

Study population and drug detection process

We included all fatal crashes resulting in immediate death (including pedestrian fatalities) in the study. All the drivers involved were taken as soon as possible to the hospital, under the control of the police, for compulsory urine testing to detect four major drug families (cannabis, amphetamines, opiates, and cocaine). If the test was positive or impossible a blood sample was taken. This information was associated with the blood alcohol concentration in the police reports.

These reports provided 10748 drivers who had had full tests for drugs and alcohol. We considered urinary screening for drugs as positive above a concentration of $1000 \mathrm{ng} / \mathrm{ml}$ of urine for amphetamines, $300 \mathrm{ng} / \mathrm{ml}$ for cocaine and opiates, and 50 $\mathrm{ng} / \mathrm{ml}$ of acid tetrahydrocannabinol for cannabis. We considered blood tests for drugs (using gas chromatography-mass spectrometry) positive above a concentration of $50 \mathrm{ng} / \mathrm{ml}$ for amphetamines and cocaine, $20 \mathrm{ng} / \mathrm{ml}$ for opiates, and $1 \mathrm{ng} / \mathrm{ml}$ of $\Delta^{9}$ tetrahydrocannabinol for cannabis. We considered drivers negative if their urine tests were negative or their blood concentrations below these thresholds. However, during the analyses of dose and effect, we no longer considered non-null below threshold concentrations as "negative."

\section{Objectives and study design}

We estimated the relative risk of responsibility for fatal crashes while driving under the influence of cannabis and evaluated the corresponding share of fatal crashes. This also implied estimating the prevalence of cannabis in the driving population (drivers not involved in a crash). Under certain conditions, these variables can be estimated from a case-control study. ${ }^{14}$

Cannabis intoxication may favour fatal crash occurrence in two ways: either by increasing the risk of causing a crash (resulting in death), or by increasing the risk of being killed (in a crash caused by another driver) because of greater vulnerability. Our analysis only dealt with the first hypothesis. We considered the 
second hypothesis only as a potential source of selection bias of the control group. As such, we evaluated drivers' risk of being responsible for a fatal crash, resulting in their own death or that of another person.

We sought a dose-effect relation between responsibility and cannabis dose, took potential confounding factors into account (focusing specifically on alcohol), and evaluated the representativeness of the cases and controls.

\section{Assessment of responsibility}

We determined responsibility of the driver by adapting the method proposed by Robertson and Drummer, ${ }^{15}$ which takes into account the different factors liable to reduce driver responsibility. We considered several categories of factors: driving offences, responsibility assignment by the police, factors characterising vehicle and road conditions, and crash types. We also asked experts to evaluate the responsibility for a representative subsample of 2683 drivers in a crash involving two or more vehicles. We carried out these two evaluations without considering alcohol and drug intoxication or related factors, such as sex and age. We therefore compared the two responsibility assessments for this common subsample.

\section{Selection of cases and controls}

The cases were the 6766 drivers at fault, including those responsible for their own death. We selected the controls from the 3982 drivers not at fault (a smaller sample because in single vehicle crashes, the driver was generally at fault). In reality, only a comparison with the driving population allowed us to estimate relative risks by using odds ratios (as the event of interest must be a rare event). We therefore used the exposure prevalence estimated from this control group to estimate corresponding attributable risks. As previously found with alcohol, ${ }^{16}$ analysis showed a significant increase in the risk of death of drivers not at fault who tested positive to cannabis. ${ }^{17}$ Because this phenomenon would lead to a selection bias compared with the driving population-because of the over-representation of crashes in which the only person killed is a driver detected as positive for cannabis (or alcohol)-we excluded the 976 drivers not at fault who were the only fatally injured parties in the crash and therefore selected 3006 controls who were neither at fault nor the only fatally injured party (figure 1).

\section{Validation of cases and controls}

We used the police national database of injury crashes (all crash severities) to identify the 112181 drivers not at fault who were involved in a crash resulting in slight injury (a group we assumed best to represent the driving population). We standardised the prevalence for our control group according to cannabis related factors that were found to be significant between the two groups to estimate the prevalence of cannabis in this group and made the same comparison for alcohol. We discussed the representativeness of our controls on the basis of a comparison, on the one hand between these observed and standardised prevalences and on the other hand between these same prevalences for alcohol and those estimated elsewhere for the driving population by using other methods.

We also used this method when comparing our cases to the 5496 drivers at fault who were responsible for a fatal crash, who were not subjected to full drug and alcohol screening.

\section{Confounding factors}

The main variable is the positive detection of cannabis. However, considering alcohol simultaneously has a twofold advantage: it takes into account a major confounding factor, and it validates new results on drugs with analogous results on alcohol, already well represented in the literature. A dose-effect is sought for both.

The other cofactors we considered are the other three families of drugs, the driver's age and sex, the type of vehicle driven, and the time of crash. We excluded certain other factors for two reasons: they were not relevant for all vehicle types (such as

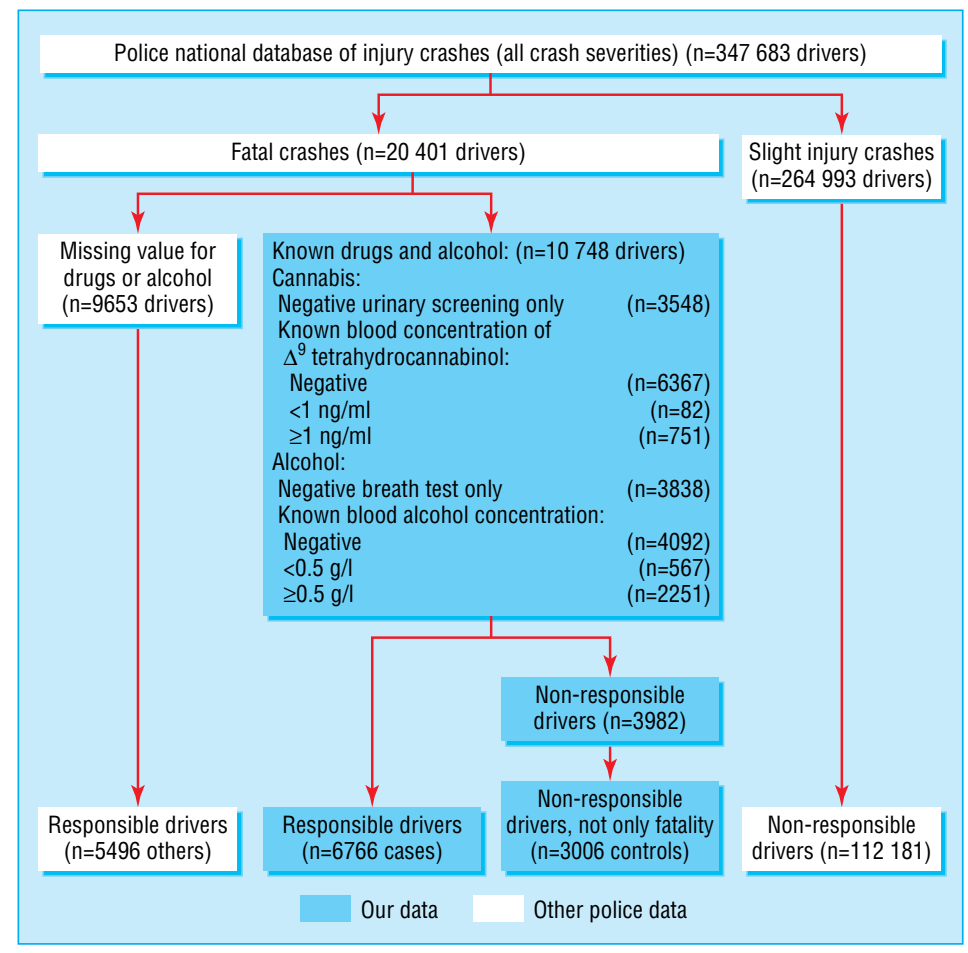

Flow of included drivers through the study 
wearing a seat belt), or they were the result of the crash (such as the number of vehicles involved), which would lead to over-adjustment. We used unconditional logistic regression to estimate odds ratios.

\section{Estimation of attributable risk}

Once we considered the representativeness of our cases and controls acceptable, and given that the relative risks were significant, we then estimated the fraction of fatal crash risks attributable to cannabis and alcohol. We used the bootstrap method to estimate confidence intervals. We calculated attributable risk from estimated odds ratios and prevalence rates for each of 2000 replications. The 95\% confidence interval limits were the 2.5th and 97.5th percentiles of the bootstrap distribution, which avoids any normality assumption. ${ }^{18}{ }^{19}$ In the absence of certainty regarding the confounding role of certain cofactors, we propose a double estimation, adjusted for all the cofactors used in the analysis, or on cannabis and alcohol alone (and other drugs, when appropriate). We used SAS, version 9 (SAS Institute Corporation, Cary, NC, 2003) for our analysis.

\section{Results}

Of the 9772 drivers studied, 681 were positive for cannabis $(7.0 \%)$ and 2096 for alcohol (21.4\%), including 285 for both $(2.9 \%)$. The other three families of drugs were, proportionally, more often associated with cannabis than with alcohol (table 1). Men, more often involved in crashes than women, were also more often positive for both cannabis and alcohol, as were the youngest drivers, and users of mopeds and motorcycles. Positive detection was more commonly associated with nighttime crashes.

Agreement between the two responsibility evaluation methods was seen to be satisfactory ( $\kappa$ test 0.71 ). Table 2 shows the estimated odds ratios of responsibility, according to the Robertson and Drummer method, associated with drugs and alcohol. Cannabis was significantly related to responsibility of the driver. Using expert evaluation did not modify this non-adjusted odds ratio $(2.87,95 \%$ confidence interval 2.07 to 3.97$)$.

Amphetamines, cocaine, and alcohol were also significantly related to responsibility, although opiates were not. We highlighted a significant dose effect for cannabis (and for alcohol), adjusted or not for alcohol (respectively for cannabis), shown in table 3 (test for trend for non-null concentrations or $\Delta^{9}$ tetrahydrocannabinol $\mathrm{P}<0.01$; for non-null blood alcohol concentration $\mathrm{P}<0.001)$. These dose effects were taken into account in the rest of the analysis.

Case drivers and control drivers also differ according to sex $(\mathrm{P}<0.05)$, age $(\mathrm{P}<0.001)$, vehicle type $(\mathrm{P}<0.001)$, and time of crash $(\mathrm{P}<0.001)$. We performed multivariate analysis to adjust the relation between responsibility and blood concentration of $\Delta^{9}$ tetrahydrocannabinol for these cofactors, added to blood alcohol concentration, amphetamines, and cocaine. In addition to blood concentrations of $\Delta^{9}$ tetrahydrocannabinol $(\mathrm{P}<0.001)$ and alcohol $(\mathrm{P}<0.001)$, shown in table 3 , the final model included driver's age $(\mathrm{P}<0.001)$, type of vehicle $(\mathrm{P}<0.001)$, and time of crash $(\mathrm{P}<0.001)$. It excluded amphetamines $(\mathrm{P}=0.20)$, cocaine $(P=0.07)$, and driver's sex $(P=0.08)$. Table 4 shows adjusted odds ratios associated with these cofactors, included or not in the final model. No interaction reached significance, particularly that between blood concentrations of $\Delta^{9}$ tetrahydrocannabinol and alcohol $(\mathrm{P}=0.99)$ : we estimated the adjusted joint effect corresponding to blood concentrations of both $\Delta^{9}$ tetrahydrocannabinol and alcohol present at any dose to be 14.0 (8.00
Table 1 Characteristics for all drivers, and for those tested positive for cannabis and for alcohol. Values are numbers (percentages) of drivers

\begin{tabular}{|c|c|c|c|}
\hline & $\begin{array}{l}\text { All drivers } \\
(\mathrm{n}=9772)\end{array}$ & $\begin{array}{c}\Delta^{9} \\
\text { tetrahydrocannabinol } \\
\geq 1 \mathrm{ng} / \mathrm{ml}(\mathrm{n}=681)\end{array}$ & $\begin{array}{l}\text { Alcohol } \geq 0.5 \mathrm{~g} / \mathrm{l} \\
\quad(\mathrm{n}=2096)\end{array}$ \\
\hline \multicolumn{4}{|l|}{ Blood concentration of drugs: } \\
\hline $\begin{array}{l}\Delta^{9} \text { tetrahydrocannabinol } \geq 1 \\
\mathrm{ng} / \mathrm{ml}\end{array}$ & $681(7.0)$ & $681(100.0)$ & $285(13.6)$ \\
\hline Amphetamines $\geq 50 \mathrm{ng} / \mathrm{ml}$ & $47(0.5)$ & $20(2.9)$ & $17(0.8)$ \\
\hline Cocaine $\geq 50 \mathrm{ng} / \mathrm{ml}$ & $22(0.2)$ & $9(1.3)$ & $5(0.2)$ \\
\hline Opiates $\geq 20 \mathrm{ng} / \mathrm{ml}$ & $83(0.8)$ & $23(3.4)$ & $14(0.7)$ \\
\hline $\begin{array}{l}\text { Blood concentration of alcohol } \\
\geq 0.5 \mathrm{~g} / \mathrm{l}\end{array}$ & 2096 (21.4) & $285(41.9)$ & $2096(100.0)$ \\
\hline Male sex & 8298 (84.9) & $643(94.4)$ & 1951 (93.1) \\
\hline Female sex & $1474(15.1)$ & $38(5.6)$ & $145(6.9)$ \\
\hline \multicolumn{4}{|l|}{ Age in years: } \\
\hline$\leq 24$ & $2399(24.5)$ & $412(60.5)$ & $628(30.0)$ \\
\hline 25 to 34 & 2379 (24.3) & $199(29.2)$ & $616(29.4)$ \\
\hline 35 to 69 & 4436 (45.4) & $66(9.7)$ & $804(38.4)$ \\
\hline$\geq 70$ & $558(5.7)$ & $4(0.6)$ & $48(2.3)$ \\
\hline \multicolumn{4}{|l|}{ Vehicle type: } \\
\hline Moped & $276(2.8)$ & $35(5.1)$ & $106(5.1)$ \\
\hline Motorcycle & $816(8.4)$ & $73(10.7)$ & $233(11.1)$ \\
\hline Car & $6987(71.5)$ & $531(78.0)$ & $1678(80.1)$ \\
\hline Van & $329(3.4)$ & $17(2.5)$ & $38(1.8)$ \\
\hline Truck & 1069 (10.9) & $20(2.9)$ & $23(1.1)$ \\
\hline Other* & $295(3.0)$ & $5(0.7)$ & $18(0.9)$ \\
\hline \multicolumn{4}{|l|}{ Crash time: } \\
\hline Monday to Friday, daytime & $5330(54.5)$ & $271(39.8)$ & $581(27.7)$ \\
\hline Saturday, daytime & $1059(10.8)$ & $61(9.0)$ & $194(9.3)$ \\
\hline Sunday, daytime & $974(10.0)$ & $67(9.8)$ & $233(11.1)$ \\
\hline Sunday to Thursday, nighttime & 1228 (12.6) & $123(18.1)$ & $474(22.6)$ \\
\hline Friday night & $240(2.5)$ & $29(4.3)$ & $94(4.5)$ \\
\hline Saturday night & 941 (9.6) & $130(19.1)$ & $520(24.8)$ \\
\hline
\end{tabular}

${ }^{*}$ Including 60 bicycles.

to 24.7), very close to the value obtained from the product of the adjusted individual effects $(1.78 \times 8.51=15.1)$.

Comparing our controls with drivers not at fault involved in a slight injury crash allowed us to identify their distinguishing characteristics: driver's sex and age; type of vehicle; and place, time, and type of crash. The prevalence of cannabis in our controls was $2.8 \%$, compared with $2.9 \%$ when standardised for these variables; both these prevalences were $2.7 \%$ for alcohol.

Similarly, comparing our cases with the other drivers responsible for a fatal crash enabled us to estimate the prevalence of cannabis and alcohol for the other drivers: for cannabis, the standardised prevalence was $8.5 \%$ compared with $8.8 \%$ for the cases, and for alcohol, it was $29.3 \%$ compared with $29.8 \%$.

The adjusted fraction of fatal crashes attributable to cannabis (present at any dose) was 2.5\% (4.3\% when adjusted only for alcohol). The adjusted fraction for alcohol was 29\% and 31\% when adjusted only for cannabis. When considering only blood

Table 2 Drivers' responsibility associated with drugs and alcohol. Values are numbers (percentages) of drivers unless otherwise indicated

\begin{tabular}{lccc} 
& $\begin{array}{c}\text { Cases } \\
(\mathrm{n}=6766)\end{array}$ & $\begin{array}{c}\text { Controls } \\
(\mathrm{n}=3006)\end{array}$ & $\begin{array}{c}\text { Unadjusted odds ratio } \\
(95 \% \mathrm{Cl})\end{array}$ \\
\hline Blood concentration of drugs: & & & \\
\hline $\begin{array}{l}\Delta^{9} \text { tetrahydrocannabinol } \geq 1 \\
\mathrm{ng} / \mathrm{ml}\end{array}$ & $596(8.8)$ & $85(2.8)$ & $3.32(2.63$ to 4.18$)$ \\
\hline Amphetamines $\geq 50 \mathrm{ng} / \mathrm{ml}$ & $42(0.6)$ & $5(0.2)$ & $3.75(1.48$ to 9.47$)$ \\
\hline Cocaine $\geq 50 \mathrm{ng} / \mathrm{ml}$ & $20(0.3)$ & $2(0.1)$ & $4.44(1.04$ to 19.0$)$ \\
\hline$\quad$ Opiates $\geq 20 \mathrm{ng} / \mathrm{ml}$ & $56(0.8)$ & $27(0.9)$ & $0.92(0.58$ to 1.46$)$ \\
\hline $\begin{array}{l}\text { Blood concentration of alcohol } \\
\geq 0.5 \mathrm{~g} / \mathrm{l}\end{array}$ & $2016(29.8)$ & $80(2.7)$ & $15.5(12.4$ to 19.5$)$ \\
\hline
\end{tabular}


Table 3 Odds ratios of driver responsibility associated with blood concentration of $\Delta^{9}$ tetrahydrocannabinol and alcohol

\begin{tabular}{ccc} 
No of & \multicolumn{3}{c}{ Odds ratio (95\% confidence interval) } \\
\cline { 2 - 3 } drivers & $\begin{array}{c}\text { Adjusted for } \\
\text { alcohol or } \Delta^{9} \\
\text { tetrahydrocannabinol }\end{array}$ & $\begin{array}{c}\text { Multivariate } \\
\text { model }\end{array}$ \\
\end{tabular}

Concentration of $\Delta$

tetrahydrocannabino

(ng/ml):

\begin{tabular}{|c|c|c|c|c|}
\hline Negative & 9013 & 1.00 & 1.00 & 1.00 \\
\hline$<1$ & 78 & $\begin{array}{c}2.18 \\
\text { (1.22 to } 3.89)\end{array}$ & $\begin{array}{c}1.89 \\
\text { (1.03 to } 3.47)\end{array}$ & $\begin{array}{c}1.57 \\
(0.84 \text { to } 2.95)\end{array}$ \\
\hline 1 to 2 & 298 & $\begin{array}{c}2.54 \\
\text { (1.86 to } 3.48)\end{array}$ & $\begin{array}{c}2.04 \\
(1.47 \text { to } 2.84)\end{array}$ & $\begin{array}{c}1.54 \\
(1.09 \text { to } 2.18)\end{array}$ \\
\hline 3 to 4 & 143 & $\begin{array}{c}3.78 \\
\text { (2.24 to } 6.37)\end{array}$ & $\begin{array}{c}2.78 \\
\text { (1.61 to } 4.78)\end{array}$ & $\begin{array}{c}2.13 \\
(1.22 \text { to } 3.73)\end{array}$ \\
\hline$\geq 5$ & 240 & $\begin{array}{c}4.72 \\
\text { (3.04 to } 7.33)\end{array}$ & $\begin{array}{c}3.06 \\
\text { (1.93 to } 4.84)\end{array}$ & $\begin{array}{c}2.12 \\
(1.32 \text { to } 3.38)\end{array}$ \\
\hline Present at any dose & 759 & $\begin{array}{c}3.17 \\
\text { (2.56 to } 3.94)\end{array}$ & $\begin{array}{c}2.37 \\
(1.89 \text { to } 2.97)\end{array}$ & $\begin{array}{c}1.78 \\
(1.40 \text { to } 2.25)\end{array}$ \\
\hline \multicolumn{5}{|l|}{$\begin{array}{l}\text { Blood concentration } \\
\text { of alcohol }(\mathrm{g} / \mathrm{l}) \text { : }\end{array}$} \\
\hline Negative & 7181 & 1.00 & 1.00 & 1.00 \\
\hline$<0.5$ & 495 & $\begin{array}{c}3.41 \\
\text { (2.67 to } 4.35)\end{array}$ & $\begin{array}{c}3.30 \\
\text { (2.59 to } 4.22)\end{array}$ & $\begin{array}{c}2.70 \\
\text { (2.10 to } 3.48)\end{array}$ \\
\hline 0.5 to 0.8 & 211 & $\begin{array}{c}8.00 \\
\text { (4.80 to 13.4) }\end{array}$ & $\begin{array}{c}7.74 \\
\text { (4.64 to } 12.9)\end{array}$ & $\begin{array}{c}6.29 \\
(3.74 \text { to } 10.6)\end{array}$ \\
\hline 0.8 to 1.2 & 304 & $\begin{array}{c}9.32 \\
\text { (5.91 to } 14.7)\end{array}$ & $\begin{array}{c}8.73 \\
\text { (5.53 to } 13.8)\end{array}$ & $\begin{array}{c}7.56 \\
(4.75 \text { to } 12.0)\end{array}$ \\
\hline 1.2 to 2.0 & 739 & $\begin{array}{c}15.0 \\
\text { (10.4 to } 21.6)\end{array}$ & $\begin{array}{c}14.1 \\
(9.79 \text { to } 20.2)\end{array}$ & $\begin{array}{c}13.2 \\
\text { (9.11 to 19.1) }\end{array}$ \\
\hline$\geq 2.0$ & 842 & $\begin{array}{c}41.8 \\
\text { (24.1 to } 72.4)\end{array}$ & $\begin{array}{c}40.0 \\
\text { (23.1 to } 69.4)\end{array}$ & $\begin{array}{c}39.6 \\
\text { (22.7 to 68.9) }\end{array}$ \\
\hline Present at any dose & 2591 & $\begin{array}{c}9.97 \\
\text { (8.44 to } 11.8)\end{array}$ & $\begin{array}{c}9.50 \\
\text { (8.04 to 11.2) }\end{array}$ & $\begin{array}{c}8.51 \\
\text { (7.15 to 10.1) }\end{array}$ \\
\hline
\end{tabular}

${ }^{*}$ Included variables: blood concentration of $\Delta^{9}$ tetrahydrocannabinol, blood concentration of alcohol, age, vehicle type, time of crash.

alcohol concentration over $0.5 \mathrm{~g} / \mathrm{l}$, it was $25 \%$ and $27 \%$ respectively (table 5).

\section{Discussion}

The risk of responsibility for fatal traffic crashes while driving under the influence of cannabis has a significant dose effect that shows a causal relation between cannabis and crashes.

\section{Strengths of the study}

We used a case-control study to overcome the difficulty of finding appropriate controls for the cases involved in road crashes. Cannabis and alcohol prevalences, when standardised according to the factors distributed differently between the controls and drivers not at fault involved in crashes resulting in slight injury, were found to be very close to the raw values. Additionally, the prevalence of alcohol in the controls is comparable to that estimated for the French driving population (about 2.5\%) ${ }^{20}$ when other methods are used. These similarities help validate the comparison of our controls with the driving population, and in particular the prevalence of cannabis observed as an acceptable estimation for the driving population. This approach, which excludes certain over-represented drivers not at fault from the control group, also helps to answer questions raised by some authors who obtain higher odds ratios when comparing cases to the driving population (not involved in crashes), than when comparing the same cases to drivers not at fault (involved in crashes). ${ }^{21}$

We did not exclude any drivers at fault and therefore took into account the overall increase in cannabis related risk in causing crashes fatal to either the individual or to others. This
Table 4 Adjusted odds ratios of driver responsibility associated with the cofactors of blood concentrations of $\Delta^{9}$ tetrahydrocannabinol and alcohol either included in the final model (age, vehicle type, crash time) or not (amphetamines, cocaine, sex). Values are numbers (percentages) of drivers unless otherwise indicated

\begin{tabular}{|c|c|c|c|}
\hline & $\begin{array}{c}\text { Cases } \\
(\mathrm{n}=6766)\end{array}$ & $\begin{array}{l}\text { Controls } \\
(\mathrm{n}=3006)\end{array}$ & $\begin{array}{l}\text { Odds ratio (95\% } \\
\text { confidence interval) }\end{array}$ \\
\hline \multicolumn{4}{|l|}{ Blood concentration of drugs: } \\
\hline Amphetamines $^{*} \geq 50 \mathrm{ng} / \mathrm{ml}$ & $42(0.6)$ & $5(0.2)$ & 1.96 (0.73 to 5.27$)$ \\
\hline Cocaine $^{\star} \geq 50 \mathrm{ng} / \mathrm{ml}$ & $20(0.3)$ & $2(0.1)$ & 4.23 (0.91 to 19.6) \\
\hline \multicolumn{4}{|l|}{ Sex*: } \\
\hline Male & 5780 (85.4) & $2518(83.8)$ & 1.00 \\
\hline Female & $986(14.6)$ & $488(16.2)$ & 1.12 (0.98 to 1.27$)$ \\
\hline \multicolumn{4}{|l|}{ Age in years } \\
\hline$\leq 24$ & $1941(28.7)$ & $458(15.2)$ & 1.89 (1.65 to 2.16$)$ \\
\hline 25 to 34 & $1628(24.1)$ & $751(25.0)$ & $1.03(0.91$ to 1.16$)$ \\
\hline 35 to 69 & $2751(40.7)$ & $1685(56.1)$ & 1.00 \\
\hline$\geq 70$ & $446(6.6)$ & $112(3.7)$ & 2.56 (2.04 to 3.20$)$ \\
\hline \multicolumn{4}{|l|}{ Vehicle type: } \\
\hline Moped & $255(3.8)$ & $21(0.7)$ & 3.09 (1.94 to 4.93) \\
\hline Motorcycle & $761(11.2)$ & $55(1.8)$ & 5.94 (4.47 to 7.91$)$ \\
\hline Car & $4995(73.8)$ & $1992(66.3)$ & 1.00 \\
\hline Van & $183(2.7)$ & $146(4.9)$ & 0.67 (0.53 to 0.85$)$ \\
\hline Truck & $418(6.2)$ & $651(21.7)$ & $0.41(0.36$ to 0.47$)$ \\
\hline Other & $154(1.5)$ & $141(4.5)$ & 0.62 (0.49 to 0.80$)$ \\
\hline \multicolumn{4}{|l|}{ Crash time: } \\
\hline Monday to Friday, daytime & $3512(51.9)$ & $1818(60.5)$ & 1.00 \\
\hline Saturday, daytime & $709(10.5)$ & $350(11.6)$ & $0.73(0.62$ to 0.85$)$ \\
\hline Sunday, daytime & $695(10.3)$ & $279(9.3)$ & 0.78 (0.66 to 0.92$)$ \\
\hline $\begin{array}{l}\text { Sunday to Thursday, } \\
\text { nighttime }\end{array}$ & $917(13.6)$ & $311(10.3)$ & $0.92(0.78$ to 1.08$)$ \\
\hline Friday night & $182(2.7)$ & $58(1.9)$ & 0.74 (0.53 to 1.05$)$ \\
\hline Saturday night & 751 (11.1) & $190(6.3)$ & 0.75 (0.61 to 0.91$)$ \\
\hline
\end{tabular}

*Estimates shown when individually added to the final model.

explains why we found higher risks than in studies that only include fatally injured drivers. ${ }^{21}{ }^{22}$ The increased fatality risk of drivers not at fault under the influence of cannabis or alcohol is a phenomenon that deserves further investigation. It can be partly explained by greater exposure to the secondary risk of death in a crash, via higher vulnerability (such as the use of motorised two-wheelers), riskier behaviour ${ }^{23}{ }^{24}$ (such as not wearing seat belts), or socio-economic disparities (such as the age of their vehicle), and partly by a reduced ability to avoid a crash. ${ }^{17}$

Likewise, studying only drivers at fault for whom drug and alcohol detection had been carried out could have constituted a biased sample of all drivers responsible for fatal crashes. Standardised and raw estimates of the prevalences of cannabis and alcohol were very close, which shows that differences between our cases and other drivers responsible for fatal crashes have no significant effect on prevalence estimates.

Table 5 Adjusted fractions of attributable risks of fatal crashes associated with blood concentrations of $\Delta^{9}$ tetrahydrocannabinol and alcohol. Values are percentages (95\% confidence intervals)

\begin{tabular}{lcc} 
Substance and concentration & $\begin{array}{c}\text { Adjusted for } \Delta^{9} \\
\text { tetrahydrocannabinol or } \\
\text { alcohol }\end{array}$ & Multivariate model \\
\hline $\begin{array}{c}\Delta^{9} \text { tetrahydrocannabinol }>0.0 \\
\mathrm{ng} / \mathrm{ml}\end{array}$ & $4.3(3.4$ to 5.3$)$ & 2.5 (1.5 to 3.5$)$ \\
\hline Alcohol: & $31.2(29.8$ to 32.5$)$ & $28.6(26.8$ to 30.5$)$ \\
\hline$>0.0 \mathrm{~g} / \mathrm{l}$ & $26.8(25.6$ to 28.0$)$ & $25.2(23.5$ to 26.9$)$ \\
\hline$\geq 0.5 \mathrm{~g} / \mathrm{l}$
\end{tabular}

${ }^{*}$ Includes blood concentrations of $\Delta^{9}$ tetrahydrocannabinol and alcohol, driver's age, type of vehicle, and time of crash. 
Consequently, our approach allows the estimation of the fraction of fatal crashes attributable to cannabis, providing that all drivers are taken into account. We had to consider drivers who had negative urine tests without any blood confirmation as negative. This choice is acceptable as the Syva RapidTest, a commonly used urinary test, has a sensitivity of $93 \%$ and a specificity of close to $100 \%{ }^{25}$ What is more, the odds ratios linked to urine tests alone (1.83, 95\% confidence interval: 1.47 to 2.27$)$ and to blood concentrations from tests taken immediately after the crashes $(2.85,2.03 \text { to } 4.02)^{17}$ are lower than those estimated here for all drivers. The former concerns drivers who were not killed and does not differentiate between cannabis consumers, not under its influence at the time of crash, and those who were driving really under its influence. The latter mainly concerns fatally injured drivers and therefore evaluates only an increase in risk for this subpopulation, masking the increase in risk linked to cannabis causing the death of its consumer. For most cases, the time elapsed between the crash and blood sampling was less than four hours, indicating that the results are reliable. ${ }^{25}$

We determined responsibility according to the Robertson and Drummer method, as used in many previous studies. This allowed us to estimate responsibility for all drivers involved in injury crashes (and thus validate the cases and controls). The high concordance with the expert responsibility assessment strongly reduced the risk of misclassification.

In other respects, for the subsample of crashes involving two or more drivers, data should also be considered as matched, and conditional logistic regression should be used. Taking these dependences into account would not significantly modify our results. ${ }^{17}$

\section{Comparison with other studies}

We used alcohol as a plausibility indicator for the results obtained for cannabis: our study concurs with previous studies on crash risk related to alcohol. ${ }^{21} 22{ }_{26}^{27}$ We were therefore able to confirm the confounding role of alcohol, although we were not able to highlight any interaction: consumption of both cannabis and alcohol would only multiply the risks related to consumption of either cannabis or alcohol alone, without specific potentiation of the effects of one by the other. This result consolidates several previous experimental and epidemiological studies. ${ }^{28}$ The existence of a dose effect gives credence to a causal relation between cannabis and road crashes.

The other cofactors may to some extent lead to over-adjustments. ${ }^{29}{ }^{30}$ This is why odds ratios and attributable risk fractions for cannabis and alcohol are given in the form of a range of values estimated by taking these cofactors into account or by ignoring them: in both cases, consumption of cannabis increases the risk of responsibility for fatal road crashes, while remaining significantly lower than the risk associated with alcohol.

\section{Limitations of the study}

It was not possible to perform an adjusted analysis of the effects of amphetamines, cocaine, and opiates, mainly because of the small number of drivers positive for these substances. This highlight, however, that these drugs are not a major issue in France at the moment (2003). Psychoactive medical drugs were only sought in the case of positive blood testing. No further study of this confounding effect was possible.

\section{Conclusions}

This study answers many questions left unanswered by previous studies, ${ }^{21}{ }^{22}{ }^{26}$ in particular by considering what some call an "at fault, not at fault" study ${ }^{31}$ as a specific case-control study.

\section{What is already known on this topic}

Cannabis consumption, even in low doses, hampers certain faculties necessary for driving a vehicle

Epidemiological studies provide conclusions that are heterogeneous and not robust enough to prove that such consumption represents a crash risk factor of significant magnitude

\section{What this study adds}

The risk of responsibility for fatal road crashes while driving under the influence of cannabis has a significant dose effect that shows a causal relation between cannabis and crashes

Reliable estimates of the share of fatal crashes attributable to cannabis and alcohol enable comparison of the respective road safety issues

However, in addition to the number of deaths linked to the responsibility of drivers, further work should include the share of all deaths attributable to the greater vulnerability of users under the influence of cannabis. This latter calculation was possible for drivers but is yet to be shown for other road users, namely passengers and pedestrians.

We thank the steering committee representatives of the French Home Office and Ministries of Defence, Justice, Transport, and Health. We also thank the members of the Scientific Committee (S Dally, C Dussault, T Harding, M Kaminski, E Lagarde, A Sasco); the French National Interministerial Road Safety Observatory (ONISR) and the French organisation TransPV that made their data available to us; the French Monitoring Centre for Drugs and Drug Addiction (OFDT) for its logistical support; and K Hodson, R Driscoll, and L Cant for their English mother tongue.

Contributors: BL designed the study, carried out the statistical analyses, contributed to the interpretation of the results, wrote the paper, and is the guarantor. BG and JLM carried out further statistical analyses and contributed to the study design, interpretation of the results, and writing of the paper. $\mathrm{MBB}$ contributed to the interpretation of the results and critical review of the paper. Other members of the SAM Group research team who contributed to obtaining the results are: $\mathrm{L}$ Campione, $\mathrm{R}$ Driscoll, $\mathrm{T}$ Hermitte, T Phalempin, D Villeforceix (CEESAR); JY Forêt-Bruno, Y Page (Lab PSA Peugeot Citroën/Renault); F Facy, M Rabaud (INSERM); P Chapuis, C Filou, K Fouquet, Y Gourlet, E Perez, J F Peytavin, P Van Elslande (INRETS); H Martineau (OFDT); C Got.

Funding: The French Ministry of Health (DGS) funded this study, with additional funding from the National Institute for Health and Medical Research (INSERM) and the French National Institute for Transport and Safety Research (INRETS). The Ministry of Justice funded the screening process. The Home Office and the Ministry of Defence financed the data collection.

Competing interests: None declared.

1 Moskowitz H. Marihuana and driving. Acc Anal Prev 1985;17:323-45.

2 Berghaus G, Sheer N, Schmidt P. Effects of cannabis on psychomotor skills and driving performance, a meta-analysis of experimental studies. In: Kloeden CN, AJM, Road Accident Research Unit, the University of Adelaide, ed. Proceedings of 13 th International Accident Research Unit, the University of Adelaide, ed. Proceedings

3 Smiley A. The Health Effects of Cannabis. In: KH, ed. Marijuana: on-road and driving simulator studies. Toronto: Centre for addiction and mental health, 1998:526.

simulator studies. Toronto: Centre for addiction and mental health, 1998:526. formance, and simulated driving. Behav Pharmacol 1998;9:599-609.

5 Sexton B, Turnbridge R, Brook-Carter N, Jackson P, Wright K. The influence of cannabis on driving. TRL Report 477, 2000:106.

6 Lamers C, Ramaekers J. Visual search and urban city driving under the influence of marijuana and alcohol. Maastricht: National Highway Transport Safety Administration, 2000. (US DOT HS 809 020.)

7 Robbe H, O'Hanlon J. Marijuana, alcohol and actual performance. Maastricht, Netherlands: National Highway Transport Safety Administration, 1999. (US DOT HS 808 939.)

8 Bates MN, Blakely TA. Role of cannabis in motor vehicle crashes. Epidemiol Rev 1999;21(2):222-32

9 Mann R, Brands B, Macdonald S, Stoduto G. Impacts of cannabis on driving: An analysis of current evidence with an emphasis on Canadian data. Ontario: Road Safety and Motor Vehicle Regulation, 2003. 
10 Huestis M, Henningfield J, Cone E. Blood cannabinoids. I. Absorption of THC and Formation of 11-OH-THC and THCCOOH during and after smoking Marijuana. $J$ Analyt Toxicol 1992;16:276-82.

11 Longo MC, Hunter CE, Lokan RJ, White JM, White MA. The prevalence of alcohol, cannabinoids, benzodiazepines and stimulants amongst injured drivers and their role in driver culpability. Part I: the prevalence of drug use in drivers, and characteristics of drug-positive group. Accid Anal Prev 2000;32:613-22.

12 Drummer OH, Gerastomoulos J, Batziris H, Chu M, Caplehorn J, Robertson MD, et al. The incidence of drugs in drivers killed in Australian road traffic crashes. Forensic Science International 2003; 134:154-62.

13 Ramaekers JG, Berghaus G, Van Laar M, Drummer OH. Dose related risk of moto vehicle crashes after cannabis use. Drug Alcohol Dependence 2004;73:109-19.

14 Coughlin S, Benichou J, Weed D. Attributable risk estimation in case-control studies. Epidemiol Rev 1994;16:51-64.

15 Robertson MD, Drummer OH. Responsibility analysis: a methodology to study the effect of drugs in driving. Accid Anal Prev 1994;26:243-7.

16 Evans L. Traffic safety and the driver: Van Nostrand Reinhold, New York, 1991.

17 Laumon B, Gadegbeku B, Martin JL, the SAM group. Stupéfiants et accidents mortels de la circulation routière (Projet SAM), Partie III: analyse épidémiologique [Drugs and fatal road raffic accidents (SAM Project), Part III: epidemiological analysis]. Paris: OFDT ed, 2005 .

18 DiCiccio T, Efron B. Bootstrap confidence intervals. Stat Sci 1996;11:189-228.

19 Llorca J, Delgado-Rodriguez M. A comparison of several procedures to estimate the confidence interval for attributable risk in case-control studies. Stat Med 2000;19:108999.

20 ONISR. La sécurité routière en France. Bilan de l'année 2003 [Road safety in France. 2003 report]. Paris: Rapport annuel de l'observatoire, 2003:137.

21 Dussault C, Brault M, Bouchard J, Lemire AM. The contribution of alcohol and other drugs among fatally injured drivers in Quebec; some preliminary results. Alcohol,Drugs and Traffic safety. Quebec: SAAQ, 2002:423-30.

22 Drummer OH, Gerastomoulos J, Batziris H, Chu M, Caplehorn J, Robertson MD, et al The involvement of drugs in drivers of motor vehicles killed in Australian road traffic crashes. Accid Anal Prev 2004:36:239-48.

23 Assailly J-P, Biecheler M-B. Conduite automobile, drogues et risque routier [Driving, drugs and road risk]. Arcueil: INRETS, 2002:87.
24 Everett SA, Lowry R, Cohen LR, Dellonger AM. Unsafe motor vehicle practices among substance-using college students. Accid Anal Prev 1999;31:667-73.

25 Verstraete A. Road traffic and psychoactive substances-results of CERTIFED and ROSITA projects. Brussels: Council of Europe, 2004:155-64.

26 Longo MC, Hunter CE, Lokan RJ, White JM, White MA. The prevalence of alcohol, cannabinoids, benzodiazepines and stimulants amongst injured drivers and their role in driver culpability. Part II: The relationship between drug prevalence and drug concentration, and driver culpability. Accid Anal Prev 2000;32:623-32.

27 Terhune KW. An evaluation of responsibility analysis for assessing alcohol and drug crash effects. Accid Anal Prev 1983;15:237-46.

28 Institut national de la santé et de la recherche médicale (INSERM). Cannabis:quels effets sur le comportement et la santé ? [Cannabis: What effects on behaviour and health?]. Paris: sur le comportement et la santé ? [Cannabis: What effects

29 Rothman KJ, Greenland S. Modern epidemiology. 2nd ed. Philadelphia: LippincottRaven, 1998 .

30 Breslow N, Day N. Statistical methods in cancer research, volume 1-the analysis of case-control studies. Lyon: International Agency for Research on Cancer Scientific Publication, 1980.

31 Davis GA, Gao Y. Statistical methods to support induced exposure analyses of traffic accident data. Transportation Res Rec 1995;1401:43-9.

(Accepted 27 September 2005)

doi 10.1136/bmj.38648.617986.1F

French National Institute for Transport and Safety Research (INRETS),

Epidemiological Research and Surveillance Unit in Transport, Occupation and Environment (UMRESTTE), 25 avenue François Mitterrand, F-69675 Bron Cedex Bernard Laumon senior researcher

INRETS/Université Claude Bernard Lyon 1 (UCBL)/Institut de Veille Sanitaire (InVS)/UMRESTTE

Blandine Gadegbeku research engineer

Jean-Louis Martin senior researcher

Marie-Berthe Biecheler senior researcher

Correspondence to: B Laumon bernard.laumon@inrets.fr 